\title{
CLASSICAL PERSON-CENTERED AND EXPERIENTIAL PERSPECTIVES ON ROGERS (1957)
}

\author{
ROBERT ELLIOTT AND ELIZABETH FREIRE \\ University of Strathclyde
}

\section{Keywords:}

According to the Web of Knowledge Citation Index (retrieved May 7, 2007), Carl Rogers's classic 1957 article, has been cited at least 1009 times since 1980 (the year citation indexing began). Returning to this central paper in the history of psychotherapy and psychotherapy research is a sobering experience. In this 9-page paper, Rogers foreshadows most of the future history of PersonCentered approach:

- The Process Equation, elaborated by Rogers and his colleagues over the next 10 years;

Robert Elliott and Elizabeth Freire, Counselling Unit, University of Strathclyde.

Correspondence concerning this article should be addressed to Robert Elliott or Elizabeth Freire, Counselling Unit, University of Strathclyde, Glasgow G13 1PP United Kingdom. E-mail: fac0029@gmail.com
- The research program that dominated the field from 1957 until the early 1970s;

- The core curriculum for a generation of helping skills training in variety of fields;

- The rejection of a range of key academic and clinical standbys, including therapist technique and schools of therapy, client individual differences and diagnosis, and professional training, presaging Rogers's abandonment of academia in 1964;

- The social agenda for the future expansion of the PCA; and

- The bold claims that would be repeatedly attacked and discredited in the late 1970s.

In short, the course of the Person-Centered Approach (PCA) for the next 50 years is contained in this classic article, including, paradoxically, the seeds of its eclipse in mainstream North American 1980s psychology, of its continuing appeal in the United Kingdom, European and elsewhere, and of its revival and reformulation in 1990s and 2000s. In this paper, we will present two perspectives of the legacy of Rogers (1957), one classical person-centered (Freire) and one process-experiential (Elliott). These two perspectives represent two major and distinct views of Rogers's legacy from within his direct intellectual and therapeutic descendents.

\section{A Classical Person-Centered Perspective (Freire)}

Although Rogers's 1957 paper has been the most well-known and influential of Rogers's research papers, it conveys just a small, yet crucial, fragment of his theory of personality change. In this paper, Rogers presented the conditions for therapeutic change out of their original theoretical context, very "briefly and factually," and without any explanatory statements. In hindsight, it is apparent that this strategy was a two-sided sword. On one hand, the 1957 paper functioned as an integrative or pan-theoretical statement (Bozarth, 1998), presenting the conditions of empathy, unconditional positive regard, and congruence as con- 
structive of personality change for any therapeutic situation in which they were applied. Surely, the wide impact and influence of Rogers's hypothesis on the field of psychotherapy research were due to its integrative character. The large body of research yielded by Rogers's hypothesis was not meant to examine client-centered therapy, but to investigate the conditions as presented in any therapeutic approach. On the other hand, due to its lack of explanatory material and theoretical context, the integrative statement was easy to interpret as a mere set of rules, or shallow principles, to be followed in a mechanical way, and this interpretation was very detrimental for the later development of personcentered therapy.

In hindsight, in the current post-positivist zeitgeist, we can also regret Rogers's reliance on naïve objectivism in formulating his hypothesis. Rogers's remarkable efforts to present operational definitions of the conditions for therapeutic change were cast in the logical positivism of the Circle of Vienna. Moreover, the overall "if-then" framework of the hypothesis is nowadays recognizable as a determinist, reductionist account of the complexity, richness, and unpredictability of the therapeutic process. However, at the time when Rogers outlined his theory, the postpositivistic developments in epistemology and philosophy of science were just beginning and unknown in North American psychology. It is noteworthy, though, that despite Rogers's subscription to the objectivist trappings of logical positivism, he became a advocate of qualitative research and developed a truly phenomenological theory of personality.

Despite these controversial features, Rogers's hypothesis had a revolutionary impact on the field of psychotherapy. The aspects of Rogers's work that were revolutionary in his time, and that can be considered still revolutionary and radical nowadays, can be summarized as follows:

(1) The therapist's endeavor is a "way of relating/being," rather than a "way of doing." In fact, Rogers's statement conveys a radical departure from the medical model and its "specificity" paradigm. No specific techniques, no specific treatment is required for client's specific problems/ disorders.

(2) In an apparent paradox, acceptance brings about change. Rogers's hypothesis states that if the therapist, instead of attempting to change the client, strives to accept the client unconditionally, change will follow naturally.

(3) The condition of empathy challenges the general assumption in the field that psychodiagnosis is essential for effective psychotherapy.

The last paragraph of Rogers's hypothesis is probably the most controversial element of his formulation: "No other conditions are necessary. If these six conditions exist, and continue over a period of time, this is sufficient. The process of constructive personality change will follow" (1996). The "sufficiency" of the three therapist attitudinal conditions (the so-called core conditions) and the correspondent principle of nondirectivity is today the pivotal point of dissension within the person-centered community. However, the diversity of interpretations of Rogers's hypothesis and the distinct ways of applying it to practice goes far beyond the issue of nondirectivity. In fact, person-centered therapy is today generally seen as one "nation" with many distinct "tribes" (Sanders, 2004). It is interesting to note that what seems to attract and to unite practitioners, academics, and scholars with such diverse viewpoints is the sheer revolutionary dimension of Rogers's work. His ideas were revolutionary in 1957 and are perhaps even more revolutionary today. They are hard to fit into the system. Rogers's postulate of the six necessary and sufficient conditions for therapeutic personality change defies the medical model, with its requisites of diagnosis, planning, and control of the therapeutic process. The paradox is that while its defiant and revolutionary stance has kept personcentered therapy at the fringes of the mental health system for decades, many of Rogers's ideas have at the same time been substantially assimilated (often without acknowledgment) by the mainstream psychotherapeutic approaches. Elliott's oral history below gives an account of this assimilation and the paradox it entails.

\section{An Oral History and Process-Experiential Perspective (Elliott)}

In 1976, at my first meeting of the Society for Psychotherapy Research, I sat in the audience, electrified, as Michael Lambert presented a dev- 
astating critique of research (later published as Lambert, DeJulio, \& Stein, 1978) on the relationship between the Rogerian facilitative conditions (1957) and therapy outcome, debunking and dismissing previous research reviews (in particular,

AQ: 4 Truax \& Carkhuff, 1971). Although my major therapeutic allegiance at that point was PersonCentered, it was clear to me that some kind of retrenchment was setting in.

Over the next couple of years, other critiques appeared. For example, Parloff, Waskow, and Wolfe (1978) reviewed the failings of the existing research and interpreted the existing research as pointing to client perceptions, not objective measures of the therapist conditions, as the clearest predictors of outcome, but vulnerable to confounding with outcome. At the same time, psychodynamic researchers (e.g., Gomes-Schwartz, 1978) reported that process measures, including client contributions to therapy, were better predictors of outcome than measures of therapist facilitative conditions and began championing an alternative concept, the therapeutic alliance.

By the early 1980s, mainstream academic psychologists in North America had pretty much dismissed Rogers's formulation of the therapeutic relationship as characterized by therapist genuineness, accurate empathy, and unconditional positive regard, to the point that I found it difficult to get research on therapist empathy published. In North America, at least, there was little research and theory development, and Rogers's ideas and his approach to therapy were generally in eclipse, maintained by a steadfast group of followers, mostly outside of academia.

However, during this period of eclipse, two things were happening in parallel: First, Rogers's approach continued to quietly spread and build strength in the United Kingdom, Europe (especially Germany, Austria, the Netherlands, and Belgium), Latin America, and elsewhere, as training programs, institutes, and professional organizations were formed and grew. Second, in North America, various followers and former students and colleagues of Rogers began to reformulate the basis of the approach, focusing on the client's experiencing and emotional processes. The first of these were Gendlin, Rice, Wexler, and Greenberg, but over time their ranks were joined by Elliott, Paivio, Watson, and, in Europe, Sachse, Lietaer, Leijssen, and others. From their work eventually came Focusing-Oriented Therapy (Gendlin, 1996) and Process-Experiential or
Emotion-Focused therapy (Greenberg, Rice, \& Elliott, 1993).

Rogers had always opposed professional organizations and training institutes, but after his death in 1987, more these began springing up, including a series of international scientific conferences on person-centered and experiential psychotherapies, leading in 1999 to the formation of the World Association for Person-Centered and Experiential Psychotherapy and Counseling (WAPCEPC). In 2001, Person-Centered and Experiential Psychotherapies began publishing, giving the field its first regularly published, international, academic journal.

At the same time, the past 15 years has seen an explosion of research on person-centered and experiential psychotherapies, building on Rogers's legacy as the first major psychotherapy researcher. By 2004, Elliott, Greenberg, and Lietaer were able to document 112 separate outcome studies, providing strong evidence from multiple lines of evidence for the effectiveness of therapies in the Rogerian tradition. Recently, the research evidence on the person-centered relationship conditions received an overdue reexamination as part of the APA Division 29 Task Force on Empirically-Supported Relationships, leading to the conclusion that two of Rogers's three conditions (empathy and warmth) were, in fact, substantially and consistently associated with outcome (Norcross, 2002).

Thus, after having been pronounced dead at the 25-year mark, Rogers's (1957) paper and, indeed, his whole legacy is very much alive 50 years on. This may not always be apparent in a North American context, where his ideas have been assimilated, often without acknowledgment, into mainstream applied psychology in the form of relational components in cognitive-behavioral therapy (e.g., Safran \& Segal, 1990), the new acceptance-based cognitive therapies (e.g., Hayes, Strosahl, \& Wilson, 1999) and therapeutic alliance concepts and measures (e.g., Horvath \& Greenberg, 1994). In the U.K. and Europe, the continuing influence of Rogers's ideas is much more apparent, but even here the legacy is by no means assured, as major struggles between academic cognitive-behaviorists (often allied with economy-minded government health ministers) and person-centered practitioners has arisen over the past five years. In Germany, the Netherlands, the U.K., and elsewhere, conflicts are continuing over narrow definitions of evidence-based prac- 
tice, the recognition and regulation of personcentered therapy practice and training, and coverage under national and private health insurance programs.

In these conflicts, the legacy of Rogers (1957) continues to be dual one: on the one hand, scientific research and its trappings of prediction, operational definitions, falsifiability, and careful observation; on the other hand, a set of radical statements that some of his later followers have used to justify lack of curiosity about therapist technique, rejection of politically useful quantitative outcome research, and even at times antiintellectualism. In my view, today's personcentered therapists must decide how to strike a productive balance between preserving the most valuable aspects of the classic Rogerian formulation of the 1950s and following the growing edge of the person-centered approach in the direction of more modern, experiential practice.

\section{Conclusion}

The two coauthors of this article disagree on several important points regarding the contemporary impact and relevance of Rogers (1957), including the principle of nondirectivity, the sufficiency of the therapist facilitative conditions, the importance of Rogers's other theoretical writings, the role of diagnosis and the formulation of different approaches for working with different types of clients, the optimal management of power issues between client and therapist, and the value of specifying and teaching therapist technique. These topics provide hours of interesting and challenging dialogue for our students and us. However, there is no disagreement between us that the Rogers's ideas continue to be the essential foundation of our work as therapists and trainers, that his intellectual legacy is alive and continues to develop in productive ways, that continuing research on person-centered and experiential therapies is critical, and that our continuing dialogue is useful and productive.

\section{References}

Bozarth, J. D. (1998). Person-centered therapy: A revolutionary paradigm. Ross-on-Wye, England: PCCS Books.

Elliott, R., Greenberg, L. S., \& Lietaer, G. (2004). Research on experiential psychotherapies. In M. J. Lambert (Ed.), Bergin \& Garfield's handbook of psychotherapy and behavior change (5th ed.; pp. 493-539), New York: Wiley.

GENDLIN, E. T. (1996). Focusing-oriented psychotherapy: A manual of the experiential method. New York: Guilford Press.

GoMES-Schwartz, B. (1978). Effective ingredients in psychotherapy: Prediction of outcome from process variables. Journal of Consulting and Clinical Psychology, 46, 1023-1035.

Greenberg, L. S., Rice, L., \& Elliott, R. (1993). Facilitating emotional change: The moment-by-moment process. New York: Guilford Press.

Hayes, S. C., Strosahl, K. D., \& Wilson, K. G. (1999). Acceptance and commitment therapy: An experiential approach to behavior change. New York: Guilford Press.

Horvath, A., \& Greenberg, L. (Eds.). (1994). The working alliance: Theory, research and practice. New York: Wiley.

Lambert, M. J., DeJulio, S. J., \& Stein, D. M. (1978) Therapist interpersonal skills: Process, outcome, methodological considerations, and recommendations for future research. Psychological Bulletin, 85, 467-489.

Norcross, J. (ED.). (2002). Psychotherapy relationships that work. New York: Oxford University Press.

Parloff, M., Waskow, I. E., \& Wolfe, B. E. (1978). Research on therapist variables in relation to process and outcome. In S. L. Garfield \& A. E. Bergin (Eds.), Handbook of psychotherapy and behavior change (2nd ed., pp. 233-282). New York: Wiley.

Rogers, C. R. (1957). The necessary and sufficient conditions of therapeutic personality change. Journal of Consulting Psychology, 21, 95-103.

SAFrAN, J. D., \& SEgAL, Z. V. (1990). Interpersonal process in cognitive therapy. New York: Basic.

SANDERS, P. (EDS.). (2004). The tribes of the personcentred nation: An introduction to the schools of therapy related to the person-centred approach. Ross-on-Wye, England: PCCS Books.

Truax, C. B., \& Mitchell, K. M. (1971). Research on certain therapist interpersonal skills in relation to process and outcome. In A. E. Bergin \& S. L. Garlfield (Eds.), Handbook of psychotherapy and behavior change (pp. 299-344). New York: Wiley. 